\title{
BILHARZIAL GRANULOMA OF THE CONUS MEDULLARIS AND CAUDA EQUINA
}

\author{
By Ahmed El-Banhawy, Osamah Elwan and Yehia Taher \\ Department of Neurosurgery, Ain Shams University and \\ The Department of Neurology, Cairo University, Cairo, Egypt
}

BILHARZIASIS*, or schistosomiasis, is a trematode worm infestation of man. It is estimated, according to the last W.H.O. reports, that 200 million people are infested with it in different parts of the world. Three species of these worms are prevalent in Africa, South America, the Middle East and South-East Asia; hematobium, mansoni and japonicum.

Although the main habitat of these worms is in the liver, the portal circulation and in the prostatic and visical plexuses of veins, ectopic forms of schistosomiasis are described in many other locations, the chest, skin, eye and the central nervous system.

In 1969, Chiat and Gannon were able to collect from the literature 43 cases of spinal bilharziasis, only 20 of which were histologically verified.

In Egypt, a country where schistosoma hematobium and mansoni infestation are prevalent, especially in the northern Provinces, neurologists and neurosurgeons were on the look-out during the last three years for cases of bilharziasis of the nervous system. Not a single case of infestation of the brain was encountered, but nine cases of spinal bilharziasis were detected.

\section{MATERIAL STUDIED}

During the period September I968 to September I97I, six cases of bilharziasis of the spinal canal came to the operation room, and were verified histologically. The first case proved to be a pathological curiosity of a bilharzial granuloma of the upper dorsal spine and was fully reported elsewhere (El-Banhawy, I969), the remaining five cases involved both the conus medullaris and the cauda equina.

During the same period, three further cases, all involving conus and cauda, were diagnosed clinically and serologically, and were treated by antibilharzial chemotherapy with such good results that they did not require referal to a neurosurgeon. Since these cases were not pathologically verified, they will not be included in this presentation.

The following is a summary of the case reports of the five surgically treated and pathologically verified bilharzial granulomas of the conus medullaris and the cauda equina:

Case 1. A I2-year-old schoolboy was admitted to the Department of neurosurgery, Ain Shams University, on I 5 January 1969, complaining of low back pain together with incontinence of urine and of faeces.

The condition started 6 months before admission with girdle pains below the level of the umbilicus precipitated by coughing, straining of lying in the supine or prone position.

* The term Bilharziasis refers to Dr Theodore Bilharz, the German physician who first discovered the schistosoma worms. 
Retention of urine soon followed and, after the boy was catheterised twice, urinary incontinence developed. Two weeks later, pain started to radiate from the back down the right thigh to the back of the knee. Some days later, pain also involved the left lower limb. One month later, weakness of the right leg appeared, to be followed by weakness of the left leg. Incontinence of faeces occurred 3 months later.

The patient gave no history of abdominal pain, fever or haematuria.

On examination, the boy was obviously underweight and he looked younger than his age. There was weakness of both lower limbs, more marked in the right and especially evident in the feet. Both legs were hypotonic, but there was no wasting and the tendon jerks were equally diminished on both sides. The superficial abdominal reflexes were

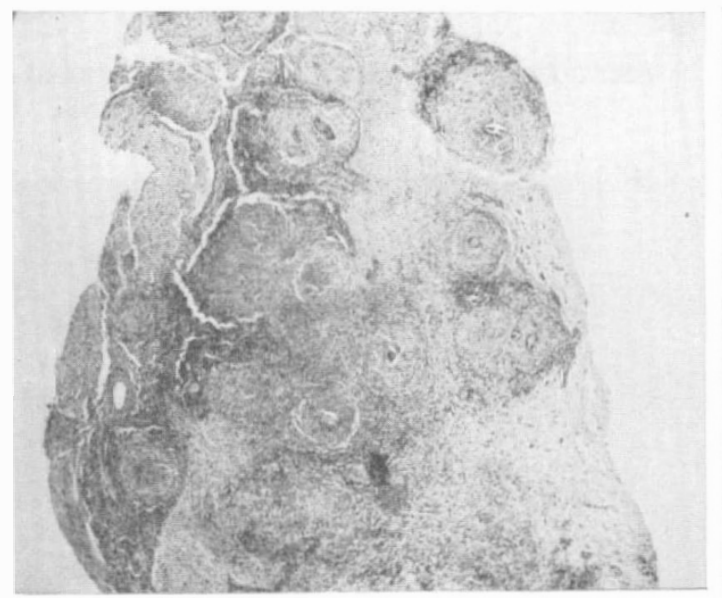

FIG. I

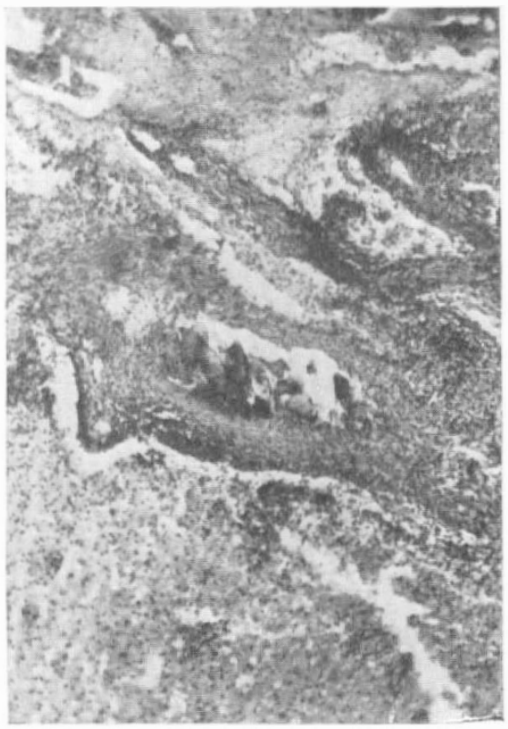

Fig. 2

Fig. I.-Appearance of bilharzial granulomata of the conus medullaris under low magnification. Ova and giant cells lie in the centres, surrounded by histiocytes, plasma cells and lymphocytes. Gliosis surround the rounded granulomai. Hematoxylin and Eosin. $\times$ I 5

Fig. 2.-Low-power view of bilharzial granulation tissue disclosing at the centre a cluster of Schistosoma hematobium ova (with terminal spines). Hematoxylin and Eosin. $\quad \times 90$

present. The right plantar response was extensor, the left was flexor. There was hypoaesthesia with a level at LI $_{\text {I }}$ with perianal anaesthesia, and vibration sense was impaired at ankles and knees. The lower dorsal and upper lumbar vertebrae were tender on palpation. Lasègue's sign was absent. He had limitation of forward and lateral flexion of the spine. There was no apparent spinal deformity.

The $\mathrm{Hb}$ was 64 per cent., the R.B.C. count was 3,500,000 per c.mm. and the total leucocytic count was 4500 per c.mm. with I2 per cent. eosinophils.

Urinalysis revealed albumin + , a few pus cells and red blood cells, as well as living bilharzia haematobium ova. Stool examination disclosed entameba histolytica cysts and a few red blood corpuscles.

Plain radiography of the lumbar spine was normal. Lumbar puncture revealed C.S.F. under normal pressure, clear and colourless. Lumbar myelography demonstrated a complete spinal block opposite LI vertebra.

Rapid correction of the anaemia and malnutrition was carried out forthwith. 
Laminectomy of TI2, LI and L2 disclosed a tense dural sac. The latter was opened in the midline posteriorly and disclosed a swollen and knobbly conus medullaris which was now incised just to the right of the midline, to expose an intramedullary gelatinous white 'tumour'. In some parts, the swelling was firm and in others soft. Pieces were taken for biopsy. The dura was left open and the wound closed in layers in the usual way.

Histological examination of the removed pieces of tissue disclosed the typical picture of bilharzial granulomas containing living bilharzia haematobium ova (figs. I and 2).

Starting from the fifth post-operative day, a course of 12 injections of tartar emetic was given.

Although there was delay in wound healing, the post-operative period was otherwise uneventful. The girdle and leg pains gradually subsided. Urinary control was achieved in 20 days. Within 6 weeks, the legs were much stronger. Bowel control was regained one and a half months after operation.

The boy was discharged two months after operation with strong legs and continent of urine and faeces.

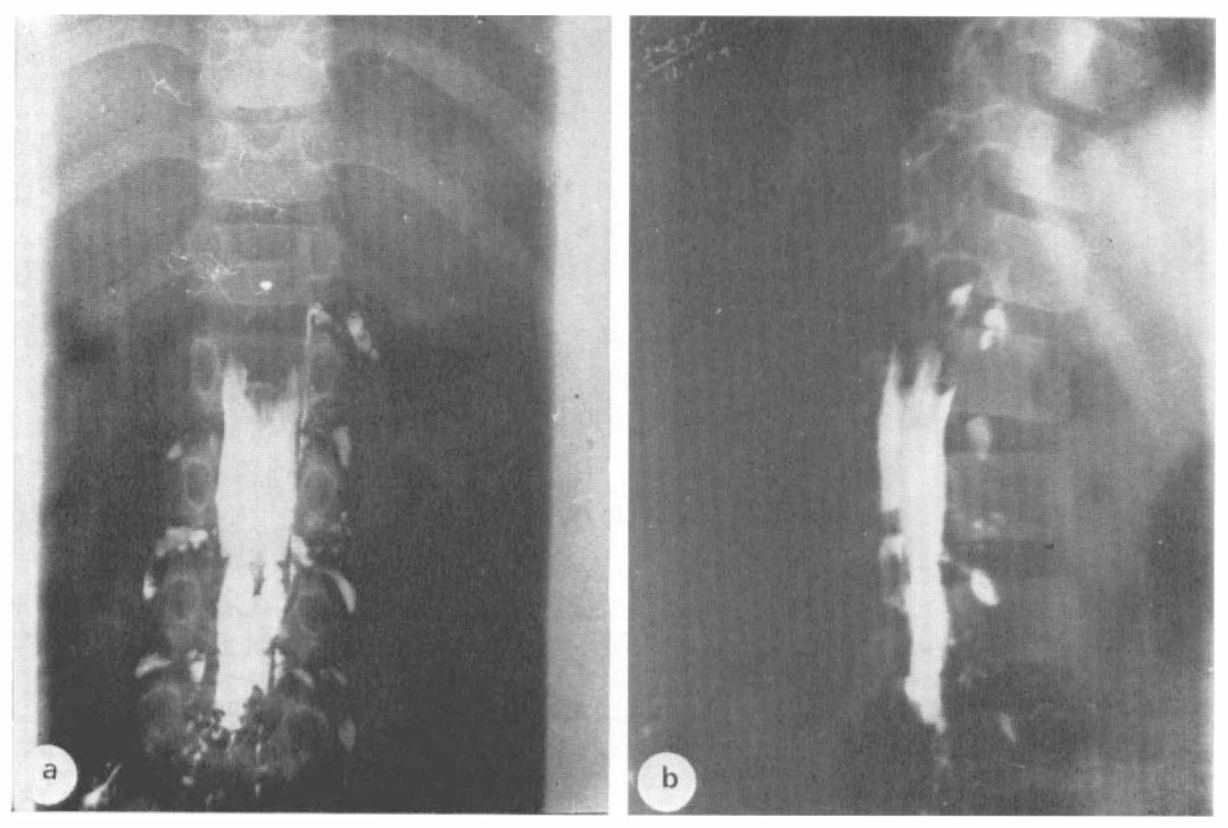

FIG. 3

A.P. (a) and lateral view (b) of lower border of the typical abrupt and trifid intramedullary myelographic bloc at LI.

Case 2. A I4-year-old peasant boy suffered from dysuria and weakness of both lower limbs for I month before presenting to Ain-Shams University Hospital.

The condition started with marked difficulty with micturition, which soon gave place to overflow incontinence. Two weeks later, the lower limbs felt heavy and this gradually progressed. At the same time, urinary control was regained to be replaced by dysuria and severe straining to evacuate the bladder.

The patient gave no history of fever, abdominal colic or haematuria.

Examination showed an underweight boy who looked smaller than his age. There was weakness of both lower limbs, more severe in the gluteal and thigh muscles. Both knee 
jerks and the left ankie jerk were brisk, while the right ankle jerk was absent. The right plantar response was extensor. There was hypoalgesia up to the first lumbar dermatome. The lumbar spine showed no clinical abnormality. The $\mathrm{Hb}$ was 58 per cent., his W.B.C.s was 5600 per c.mm., while the R.B.C. count was only 2,880,000. Eosinophils represented 3 per cent. of the total leucocytic count. Urinalysis disclosed a trace of albumin, a few pus cells and some R.B.C.s; but not ova or casts. His stools were normal. The urine and stools were repeatedly examined on several occasions for bilharzial ova, but none were found.

Plain radiographs of the dorsolumbar spine were normal, but lumbar myodil meylography (figs. $3 a$ and $b$ ) disclosed a complete block opposite TI I-TI2 vertebrae with a typical irregular trifid edge.

The clinical and radiological picture was so similar to Case I, who incidentally was still in the ward at the time of admission of this boy-that a pre-operative diagnosis of

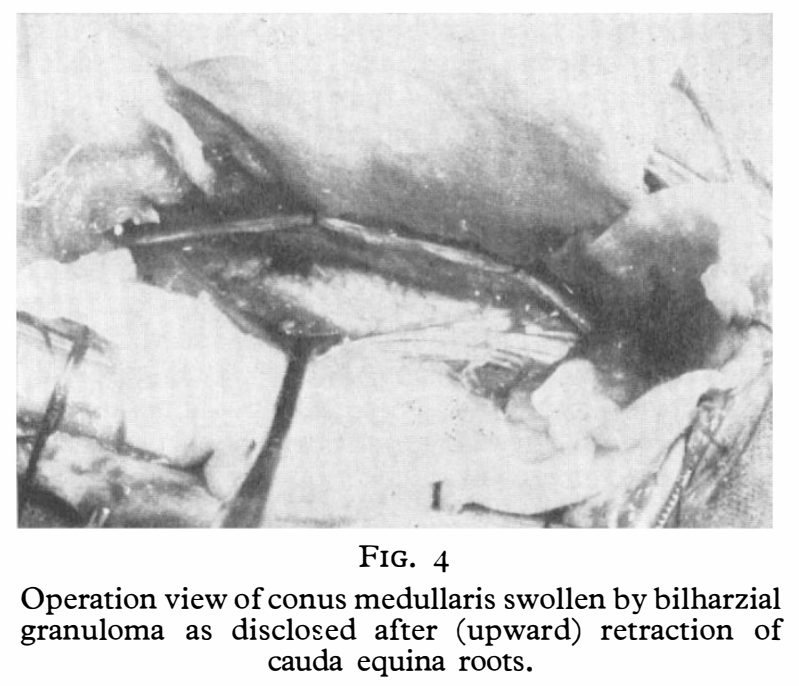

bilharzial spinal cord involvement was made. Under general anaesthesia, laminectomy of TII-L2 was carried out. The dura was opened in the midline to disclose the cauda equina roots surrounding the conus. When these roots were retracted, the swollen conus was disclosed, covered by dilated irregular vessels (fig. 4). A biopsy only was taken and the wound was closed, leaving the dura fully open. The wound was completely healed on the tenth post-operative day. Ar the same time, a course of $\mathrm{I} 2$ injections of tartar emetic was started. Both the dysuria and the paraparesis began to improve on the fifteenth postoperative day. Two months after operation, the patient was up and about almost neurologically normal.

Histological examination of the removed specimen revealed multitudes of foci of reactive granulation tissue due to lateral-spined bilharzia mansoni ova.

Case 3. A 62-year-old man was carried to Kasr El-Aini Hospital with a three-year history of paraplegia, backache, sciatic pain and incontinence of urine. He had been bed-ridden for almost one year before admission. Examination disclosed a total paraplegia with the upper level at Li. Cisternal myelography succeeded in delineating the upper and lower borders of a subtotal block opposite the lower part of TI2 vertebra with a lower limit opposite the lower part of LI vertebra, the exact location of the conus medullaris; with the distinctly irregularly trifid edges of an intramedullary swelling. At 
operation, a greyish beaded granuloma of the conus medullaris was found. It proved histologically to contain bilharzial ova of undetermined species. It was not excised and the dura was left open. Post-operative investigations including cystoscopy, sigmoidoscopy and circumoval serological tests of serum and C.S.F., failed to reveal evidence of bilharziasis.

Case 4. A i 5-year-old peasant boy complained of backache and pain extending down the legs to both feet together with burning micturition to be rapidly followed by retention of urine and dribbling. The condition had started 9 months before admission to Gamhouria Hospital and had been stationary for the last 5 months. Examination revealed slight weakness in dorsiflexion of both feet, brisk knee jerks, absent ankle jerks and slight hypoaesthesia of SI and S2 dermatomes bilaterally. Plain radiography of the lumbodorsal spine showed no abnormality, but lumbar myelography disclosed an almost complete irregular filling defect with its lower border opposite the disc space between $\mathrm{T}_{12}$ and $\mathrm{L}_{\mathrm{I}}$ vertebrae (the typical location of bilharzial granuloma). Apart from mild hypochromic microcytic anemia, the blood picture was normal. No bilharzial ova were detected in the urine, stools or from a rectal biopsy. Serological tests for bilharziasis were carried out on the C.S.F., including a circumoval test, and were strongly positive. Bilharzial granuloma of the conus medullaris was diagnosed. The patient, therefore, received a full course of tartar emetic which resulted in definite improvement in the back and sciatic pain as well as in the motor power of both feet. However, the changes in the deep reflexes and the incontinence of urine persisted. Laminectomy of TI2 and LI $_{1}$ was carried out and on opening the dura, the arachnoid was found to be opaque and adherent to the swollen vascular conus medullaris to which were adherent to the proximal parts of the $S_{1}, S_{2}$ and $S_{3}$ nerve roots. These roots were freed and the dura was left widely open after removing a portion of the conus medullaris for biopsy. The latter disclosed typical bilharzia hematobium granuloma with viable ova. A further post-operative antibilharzial course was administered. One month after operation, the patient was discharged with strong feet and only occasional precipitancy of micturition and nocturnal incontinence.

Case 5. A I2-year-old peasant girl noticed difficulty in voiding urine 3 months before coming into hospital. The condition progressed in a month to complete urinary retention requiring repeated catheterisation. Back pains shooting down both lower limbs appeared and became so severe that sleep was disturbed. Towards the end of the second month she started to limp, and weakness of both legs rapidly progressed to profound paraparesis within two weeks. When admitted to Ain-Shams University Hospital, she was unable to walk, and was carried in by her father.

Examination revealed a poorly nourished girl looking younger than her age with complete retention of urine and marked constipation. There was spastic weakness of the lower limbs with atrophy below the knees, more marked on the right side. Both knee jerks were diminished, the ankle jerks were brisk and the plantar reflexes were extensor. The superficial abdominals were present. There was slight but definite hypoaesthesia up to Ti I level. Movements of the lumbar spine were painful and the lumbar lordosis was flattened. Her $\mathrm{Hb}$ was 70 per cent., her total leucocytic count 10,600 per c.mm. with 4 per cent. eosinophils and her mean erythrocyte sedimentation rate was 25 minutes. The urine and stools contained no schistosoma ova, nor did rectal biopsy disclose any.

The clinical picture was very suggestive of bilharziasis of the epiconus and conus, and intradermal skin test and C.S.F. circumoval and precipitin tests were carried out and these were all strongly positive.

Plain radiography of the spine was normal, while myelography demonstrated a spinal block between TII and LI vertebrae (distinctly longer than in the previous cases).

Under general anaesthesia, laminectomy of $T_{I I}, T_{I 2}$ and $L_{I}$ was carried out, to reveal a tense dura, which when opened revealed whitish arachnoid adhesions concealing a typical greyish beaded granuloma occupying the epiconus, conus and extending to involve 
the proximal segments of a few cauda equina roots. Freeing of the cauda equina roots was carried out, a biopsy was taken and the dura was left widely open. Typical bilharzial granulomata containing $B$. mansoni ova were identified histologically.

The pre-operative course of antibilharzial treatment was continued post-operatively, but improvement in motor function was detected only at the end of one month and the girl was able to walk towards the end of the second month. Improvement of bladder function started three months after operation.

\section{DISCUSSION}

Schistosomiasis of the spinal canal-particularly of the epiconus, conus and cauda-should be considered in the differential diagnosis of low back and sciatic pains, of incontinence of urine and of rapidly progressive paraparesis not only in endemic areas, but even elsewhere (Wakefield, Carroll \& Speed, I968; Chiat \& Gannon, 1969). The present-day progress in transport facilities has widened the geographical distribution of many infections and parasitic diseases.

Mode of Involvement of the Conus Medullaris and Cauda Equina Region. The exact course taken by the worms and ova to reach the spinal canal is still uncertain. With the exception of the case described by Raper (1948), no adult worms have been discovered inside the spinal canal, so that we must presume that only ova are responsible for the clinico-pathological condition.

Various theories were put forward to explain how the ova could reach the spinal cord, conus and cauda (Faust, 1948). Arterial embolisation by worms or ova is nowadays attracting attention, as the skin or the conjunctiva may sometimes be involved. The large great anterior radicular artery entering the spinal canal near the lower dorsal region would explain, on the basis of the arterial embolisation theory, the site of predilection in the spinal cord; namely the conus medullaris.

However, our present studies on cadavers with heavy bilharzial infestation causing portal hypertension and wide anastomoses between the portal and systemic circulation tend to favour as a pathway for the invading ova the anastomoses between the vesical and pericolic veins on one hand and the vertebral and intraspinal venous plexuses on the other, via the sacral and lower lumbar veins. This pathway partly resembles the one taken by metastases from cancer of the prostate reaching the lumbar vertebral bodies via the vertebral venous system of Batson (I940).

Pathology. Regarding schistosomiasis of the nervous system, it is a peculiar fact that $S$. hematobium apparently affects the spinal cord exclusively, $S$. japonicum affects only the brain, while $S$. mansoni ova can invade both brain and spinal cord. This has never been explained satisfactorily.

Three varieties of bilharzial lesions of the spinal cord are described in the literature:

I. Myelitic type, in which the lesion consists of destruction, vacuolation and atrophy of the cord with little reaction around the ova (Faust, I948; Abbott \& Spencer, I953; Hutton \& Holland, I960; Marcial Rojas et al., I96I; Wakefield et al., I962; Gelfand, I967).

2. Granulomatous type, where a granuloma forms as a result of intense gliotic and fibrotic reaction to the bilharzial ova (Ross et al., I952; Gama, I953; Pepler \& Lombard, I958; El-Banhawy et al., 1969, 1970). The swelling is greyish and 
irregular, and we have found that it often has a distinct consistency at operation (El-Banhawy \& El-Sherif, I969).

3. Radicular type. This was described by Bird (1965). Its existence as a pure entity is doubted by the authors. It generally exists in association with the granulomatous variety.

Recent studies by the authors indicate that the degree of allergic reaction of the individual to bilharzial infestation will determine the pathological variety of spinal cord involvement; if the allergic reaction is intense a granuloma is produced, while if it is minimal a destructive myelitic process will ensue.

Clinical Picture. Although the clinical features of bilharzial infestation of the conus medullaris and cauda equina will vary according to the worm species; by considering the immunological and allergic reaction of the individual as well as the severity of infestation, it was possible to formulate a more or less typical clinical sequence of events.

The condition, usually occurs in a boy or a youngster aged 10-20 years, and starts with low back pain or sciatic pains which are soon followed by sphincteric disturbances rapidly progressing to incontinence. Weakness in one leg, soon to be followed by weakness of the other one, appears shortly afterwards and progresses very rapidly within days or weeks to paraparesis.

Eosinophilia is often present in the peripheral blood, while bilharzia ova may or may not be found on routine urine and stool examination. Rectal mucous membrane biopsy for bilharzial ova-a very sensitive examination to verify bilharzial infestation in general-may or may not be positive. It is a remarkable fact that in four out of the five cases operated upon, there was no evidence of bilharzial infestation outside the spinal cord.

Serological studies are particularly important, since our recent studies indicate that strongly positive precipitin and circumoval reactions to the C.S.F. as compared to the serum of the patient are specific for spinal cord involvement by bilharziasis.

Radiological Studies. Plain radiograms of the spine are as a rule normal, while myelography, using either positive or negative contrast media, generally reveals a very characteristic picture of the bilharzial granuloma. By the time the patient reaches us, a myelographic 'block' could generally be demonstrated. It is the opinion of the authors that a bilharzial granuloma will produce such specific 'myelographic features' as to warrant a confident diagnosis:

I. Specific size and location. The lesion as determined by the upper and lower limits of the block is generally of a size equal to the length of a vertebral body and is strictly located opposite the bodies of TI2 and LI. Only in Case 5 did the lesion extend up to TII, thus involving the epiconus.

2. Irregular 'trifid' edges. The borders of the granuloma, as evidenced by the shape of the edge of the block, is irregular and often characteristically specifically trifid.

3. 'Abrupt' intramedullary swelling. Intramedullary tumours often have smooth ends, i.e. the cord enlarges gradually at one end and tapers gradually at the other. In bilharzial granuloma, the swelling in the cord, which myelographically speaking is of the 'typical intramedullary variety', starts and ends abruptly over a short segment. 
Management. Scarcity of reported cases diagnosed and confirmed during life (generally at operation) makes it difficult to reach a conclusion as to the best line of treatment.

Bilharzial myelitis (demonstrated myelographically by the absence of a swelling), the less common variety, should obviously be treated by antibilharzial drugs, of which we have at present a wealth.

Bilharzial granuloma, the common type encountered in our five operated cases, is still a problem. The rapid course of the disease and the impossibility of radical excision of the infiltrating lesion in the conus medullaris or cauda equina without the complication of a serious neurological deficit dictate a combination of conservative surgery and chemotherapy. It is true that, given adequate time, a bilharzial granuloma will shrink or even disappear under specific parenteral or oral chemotherapy. However, this takes several weeks or months, long enough for neurological manifestations to become irreversible.

In the five cases, where a complete 'myelographic block' was encountered, immediate decompressive laminectomy together with freeing of cauda roots and a biopsy was carried out, with no attempt at removal of the mass. Subsequently two intensive courses of post-operative antimony tartarate were administered intravenously over the next 2 months. Good recovery was achieved in four patients and marked improvement in the fifth.

It is therefore the opinion of the authors that medical therapy is sufficient in 'myelitic' cases and probably in early granulomas. While immediate decompression followed by intensive specific antibilharzial chemotherapy is the best scheme of management for large granulomas.

\section{SUMMARY}

Although 200 million people are infested with bilharziasis all over the world, few reports of involvement of the spinal cord, conus medullaris and cauda equina by schistosoma worms or ova appear in the literature. During a period of three years, the authors came across five patients with involvement of the conus medullaris and cauda equina that were operated upon and thus verified pathologically. Case summaries of these are presented.

Clinically, the patient is generally a boy in his second decade who develops low back pain and sciatic pains and profound sphincteric disturbances. Paraparesis soon follows and often progresses rapidly to inability to walk within a few days or weeks. Examination of urine, stool and a rectal biopsy, the usual laboratory procedures to discover bilharzia ova, are much more frequently negative than positive.

Serological tests (circumoval and precepitin) of the C.S.F., especially if the titre is compared to that of the blood serum, are likely to give a specific indication of involvement of the central nervous system.

In the authors' opinion, the myelographic appearance is specific. The bilharzial granuloma produces an abrupt intramedullary block, the length of one vertebral body, strictly located opposite TI2 and LI with irregular and often trifid edges.

Bilharzial myelitis and early granuloma of the conus medullaris and cauda equina, the former rarely seen and the latter rarely diagnosed at such a stage, may be cured by antibilharzial chemotherapy (the authors used potassium antimony tartarate). 
Advanced granulomas are best managed by a combination of wide surgical decompression in addition to chemotherapy.

\section{RÉSUMÉ}

Six cas de bilharziose dans le canal médullaire sont décrits. Ces cas sont trouvés à l'opération et vérifiés hystologiquement.

Le premier cas a été celui d'un granulome bilharzial de la région dorsale haute et les cinq autres dans la région de la queue de cheval.

\section{ZUSAMMENFASSUNG}

6 Fälle von Bilharziasis des Spinalkanals werden beschrieben, die bein der Operation gefunden und histologisch verifiziert wurden. Ein Fall war ein bilharzielles Granulom der oberen Thorakalregion, die 5 weiteren Fälle befanden sich im Conus-Cauda equina Gebiet.

\section{REFERENCES}

Авbott, P. H. \& Spencer, H. (I953). Trans. Roy. Soc. Med. Hyg. 47, $22 \mathrm{I}$. Batson, O. V. (1940). Ann. Surg. I12, I38.

Bird, A. V. (1965). South Afr. Med. Fournal, 39, 158.

Chiat, A. \& Gannon, W. E. (I969). Am. F. Roentgenology, 105, 400.

El-Banhawy, A. (1969). F. Egypt, Surg. Soc. 4, I30.

El-Banhawy, A. \& El-Sherif, H. (1969). F. Egypt. Surg. Soc. 4, 254.

Faust, E. C. (1948). Am. F. Trop. Med. 28, 175.

GAMA, C. (1953). F. Int. Coll. Surg. 19, 665.

Gama, C. \& SA, J. M. (1945). Arch. Neuropsychiatr. 3, 334.

Gelfand, M. (1967). A Clinical Study of Intestinal Bilharziasis (Sch. Mansoni), in Africa, pp. I57-I60. London: Edward Arnold Publ.

Huttor, P. W. \& Holland, H. T. (1960). Brit. Med. F. 2, I93I.

Marcial-Rojas, A. A. \& Fiol, R. E. (I96I). Ann. Int. Med. 59, 215.

Pepler, W. J. \& Lombard, C. M. (1958). F. Neuropath. Exp. Neurol. 17, 656.

RAPER, A. B. (1948). E. Afr. Med. F., 25, 262.

Ross, G. L. Norcross, J. W. \& Horrax, C. (1952). New England F. Med., 246, 823.

Wakefield, G. S., Carroll, J. D. \& Speed, D. E. (I968). Brain, 85, 535. 